\title{
The Effects of Deep Water Running and Cold Water Immersion on Muscle Soreness
}

\author{
Castleberry T, BenEzra V, Deemer S, Niemann T, Foreman J
}

Exercise Physiology Laboratory; Kinesiology; Texas Woman's University; Denton, TX

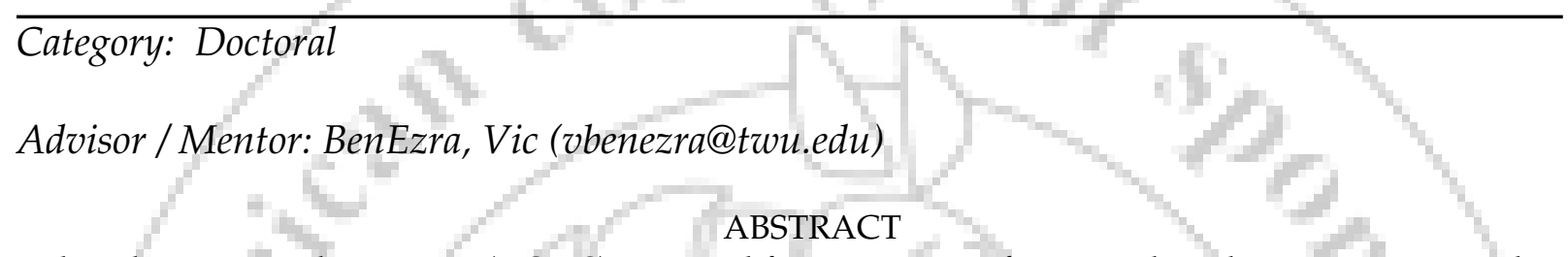

Delayed onset muscle soreness (DOMS) is caused from any type of activity that places unaccustomed loads on a muscle. Athletes are consistently pursuing methods to help decrease soreness. The purpose of this study is to evaluate the effects of deep water running (DWR) and cold water immersion (CWI) on perceived muscle soreness and creatine kinase $(C K)$ activity. Healthy participants (males $=2$, females $=12$; mean $\pm \mathrm{SD}, 22.8 \pm 4.9$ yrs; $38.0 \pm 7.8$ yrs $\left.\mathrm{VO}_{2 \max } ; 113.6 \pm 27.3 \mathrm{lbs} 1 \mathrm{RM}\right)$ completed five days of data collection. Seven days following a 1 repetition maximum (1RM), participants completed an eccentric exercise bout on the prone hamstring curl (4 sets of 10 repetitions, $120 \% 1 \mathrm{RM}$ ). Immediately following the exercise protocol, participants were randomized to one of three treatments: (1) CWI protocol (5 min in water $10^{\circ} \mathrm{C}, 2.5 \mathrm{~min}$ out, $5 \mathrm{~min}$ in water $\left.10^{\circ} \mathrm{C}\right),(2) \mathrm{DWR}$ protocol $(10 \mathrm{~min}$ at $60 \%$ age predicted heart rate $\mathrm{max}$ ), or (3) control (CON) protocol (sit quietly for $10 \mathrm{~min}$ ). Blood was collected at 4 time points: preexercise, immediately postexercise, $24 \mathrm{~h}$ postexercise, and $48 \mathrm{~h}$ postexercise. Perceived muscle soreness was measured using a visual analogue scale (0-10 pain). There were no differences in creatine kinase activity and muscle soreness across trials. Creatine kinase activity significantly increased from baseline (mean=24.5, SD=40.4 Units/L) to $48 \mathrm{~h}$ postexercise (mean=165.1, SD=85.3 Units/L) and perceived muscle soreness ( $\mathrm{pre}=.4, \mathrm{SD}=.7$, post $=5.6, \mathrm{SD}=2.2$ ) was significantly greater $48 \mathrm{~h}$ post eccentric bout $(\mathrm{p}<.001)$. There was a positive correlation ( $\mathrm{r}=.51$ ) between the change (baseline to $48 \mathrm{~h}$ post) in perceived muscle soreness and the amount of plasma CK activity, however this did not reach statistical significance $(\mathrm{p}=.06)$. Neither the DWR nor CWI treatment provided any reduction in CK activity or muscle soreness compared to the control treatment. Therefore, following a strenuous bout of eccentric exercise, there does not appear to be benefits of applying CWI or DWR compared to rest.

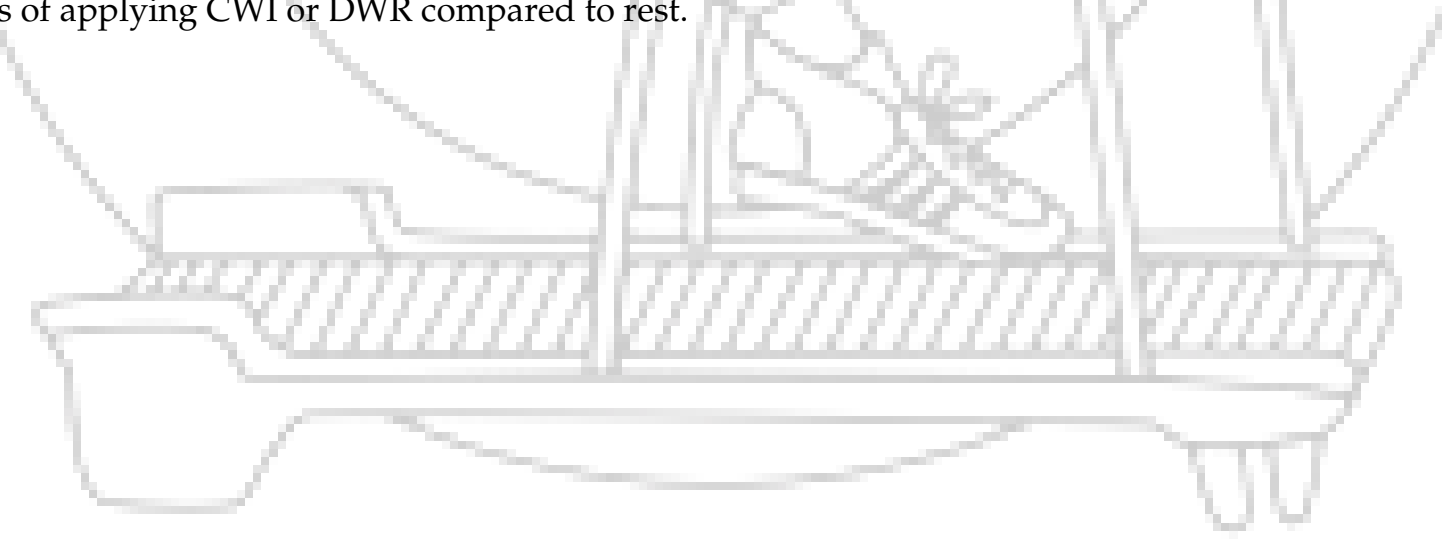

